\title{
The mammary stem cell hierarchy: a looking glass into heterogeneous breast cancer landscapes
}

\author{
Amulya Sreekumar, Kevin Roarty and Jeffrey M Rosen \\ Department of Molecular and Cellular Biology, Baylor College of Medicine, One Baylor Plaza, \\ DeBakey Building M638, Houston, Texas 77030, USA
}

Correspondence should be addressed to J M Rosen Email jrosen@bcm.edu

\begin{abstract}
The mammary gland is a dynamic organ that undergoes extensive morphogenesis during the different stages of embryonic development, puberty, estrus, pregnancy, lactation and involution. Systemic and local cues underlie this constant tissue remodeling and act by eliciting an intricate pattern of responses in the mammary epithelial and stromal cells. Decades of studies utilizing methods such as transplantation and lineage-tracing have identified a complex hierarchy of mammary stem cells, progenitors and differentiated epithelial cells that fuel mammary epithelial development. Importantly, these studies have extended our understanding of the molecular crosstalk between cell types and the signaling pathways maintaining normal homeostasis that often are deregulated during tumorigenesis. While several questions remain, this research has many implications for breast cancer. Fundamental among these are the identification of the cells of origin for the multiple subtypes of breast cancer and the understanding of tumor heterogeneity. A deeper understanding of these critical questions will unveil novel breast cancer drug targets and treatment paradigms. In this review, we provide a current overview of normal mammary development and tumorigenesis from a stem cell perspective.
\end{abstract}
Key Words
- breast
- cell signalling
- mammary gland
- stem cells
- cancer stem cells

\section{Introduction}

The mammary gland distinguishes itself from other organs since much of its development occurs after birth, allowing for adult developmental studies. Postnatal development of the mammary gland comprises stages of ductal morphogenesis, alveologenesis, lactation and involution, and is regulated by a complex interplay of systemic hormones (notably estrogen, progesterone and prolactin) and local growth factors. The observation that the mammary gland exhibits plasticity through multiple cycles of pregnancy, lactation and involution, accompanied by dynamic changes in proliferation, differentiation, cell death and tissue remodeling, suggested that there exists a renewable stem or progenitor cell population underlying these processes. It was not until the development of the cleared mammary fat pad technique by Deome et al. (1959) that it was possible to determine the ability of specific cells to effectively self-renew and differentiate to reconstitute the gland upon transplantation into an epithelium-free fat pad. This technique was originally employed to investigate whether hyperplastic alveolar nodules were the precursors of mammary tumors. Subsequent studies by Charles Daniel adapted the assay to probe for stem cells and revealed that any portion of the mammary ductal tree could regenerate the entire mammary gland, suggesting

This paper forms part of a thematic review section on Stem Cells and Cancer. The guest editor for this section was Dean Tang, The University of Texas MD Anderson Cancer Center, Smithville, TX USA 
that mammary stem cells (MaSCs) were distributed throughout the ductal network (Daniel et al. 1975). The transplanted cells responded appropriately to the hormonal environment and were able to functionally differentiate into milk-producing structures. Furthermore, serial transplantation studies using small intact pieces of mammary tissue revealed that the transplanted cells had a finite lifespan and eventually exhibited senescence in contrast to the unlimited division potential of the precancerous lesions (Daniel 1975). Additional advances involved the morphological characterization of putative MaSCs by Smith and Medina based on their pale nuclear and cytoplasmic staining properties (Smith \& Medina 1988).

It was not until hematopoietic stem cell-based experimental approaches were applied to the mammary gland that significant progress occurred in characterizing specific stem and progenitor cell populations within the mouse and human mammary glands. These studies involved methods for dissociation of mammary tissue followed by fluorescence-activated cell sorting (FACS) of cells labeled with specific antibodies against cell surface antigens, allowing for the functional analysis of particular cell populations using both in vitro colony formation and in vivo limiting dilution transplantation assays (Stingl et al. 2001, Welm et al. 2002). Although technical differences existed in these studies, e.g., the sites of transplantation in the cleared mammary fat pad for mice versus the kidney capsule for humans (Eirew et al. 2008), they collectively illustrated the similarity of the mouse and human luminal stem cell hierarchy (Shehata et al. 2012). Mammosphere assays were developed as a surrogate in vitro stem cell assay for the mammary epithelium (Dontu et al. 2003), modeled after in vitro neural stem cell-based assays where stem cells were resistant to anoikis and proliferated under suspension conditions. The assumption on which many of these studies were based was that cells dissociated from their tissue context would retain cell autonomous properties similar to those observed in the intact tissue. The holy grail of these studies was the eventual demonstration of the ability of a single cell to reconstitute the entire functional mammary gland following transplantation (Shackleton et al. 2006) as had been previously predicted (Kordon \& Smith 1998).

Analogous to the elegant genetic studies performed in the Drosophila eye, where cell-autonomous and non-cellautonomous interactions can be carefully analyzed in chimeras, the mammary gland provides a unique mammalian modeling platform for phenotypic evaluation of genetic alterations in vivo. Taking advantage of mouse genetics and the availability of wild type (WT) and knockout cells, a series of seminal experiments performed by Cathrin Brisken and colleagues have shown that progesterone receptor (PR)-positive cells can rescue PR-null cells to facilitate alveolar development, and similarly, that estrogen receptor alpha $(E R \alpha)$-positive cells can rescue ER $\alpha$-negative cells to facilitate ductal morphogenesis, both mediated by paracrine mechanisms (Brisken et al. 1998, Mallepell et al. 2006). These studies were based upon earlier observations that $\mathrm{ER} \alpha / \mathrm{PR}^{+}$cells did not proliferate in mature ducts (Clarke et al. 1997, Russo et al. 1999, Seagroves et al. 2000). Intriguingly, the analysis of an enriched population of basally-located MaSCs exhibited a lack of ER $\alpha$ and PR expression (Asselin-Labat et al. 2006), yet recent studies have illustrated the importance of steroid hormones for MaSC function (Asselin-Labat et al. 2010, Joshi et al. 2010). Transplantation of a single ER $\alpha$ negative MaSC should, therefore, a priori not be able to give rise to a mammary outgrowth unless it were able to undergo asymmetric division and ultimately give rise to an ER $\alpha$-positive luminal cell, which indeed studies have now shown to be the case.

The mammary fat pad transplantation assay has proven essential for the assessment of stem cell capacity relating to gene-specific loss- or gain-of-function studies and the assessment of self-renewal and differentiation phenotypes. Importantly, lineage tracing has unveiled distinct differences in transplantation versus in situ developmental potential of MaSCs, where the lineage commitment and developmental competence of basal cells is strongly influenced by luminal cells, highlighting the importance of considering whether single cell types or interacting populations should be utilized in the transplantation assay (Van Keymeulen et al. 2011, van Amerongen et al. 2012, De Visser et al. 2012). Indeed, this is reminiscent of the scenario in the intestine where a single $\mathrm{Lgr}^{+}$stem cell is able to give rise to organoids ex vivo, presumably through early asymmetric divisions, but forms organoids more efficiently when cultured together with a niche supporting Paneth cell (Sato et al. 2011). While paracrine communication between luminal and basal epithelial compartments is essential, stem cells are also highly dependent upon their direct interactions with the microenvironment (Inman et al. 2015). Additionally, the transplantation of tissue fragments versus dissociated single cells should also be considered, where unlike the transplantation of intact pieces of mammary tissue, single cells injected into the mammary fat pad require the ability to adhere and survive prior to engraftment - properties that are dependent on cell surface integrins. Such factors

Published by Bioscientifica Ltd. 
have been raised in recent studies that distinguish RANKL and Wnt4 functions on MaSC dynamics in vivo (Rajaram et al. 2015), discussed later in this review.

A major impetus for the advancement of mammary gland stem cell biology was the first description of breast cancer stem cells (CSCs) primarily isolated from patient derived xenografts, using similar approaches that had been applied earlier by Dick and colleagues in acute myeloid leukemia (Bonnet \& Dick 1997, Al-Hajj et al. 2003). In addition to a relatively small number of investigators initially focused on understanding the roles of stem cells in mammary gland development, numerous investigators have now entered the field, leading to an explosion of studies aimed at understanding the cell of origin of different breast cancer subtypes as well as the mechanisms responsible for therapeutic resistance and metastasis. Thus, the application of the stem cell paradigm to solid cancers and its potential importance in both etiology and treatment has led to a better appreciation of the potential mechanisms responsible for both inter- and intratumoral heterogeneity in breast cancer (Rosen \& Jordan 2009). In the following review, we will discuss several of these concepts in detail by focusing primarily on the extensive work performed in mouse models of mammary gland development and tumorigenesis, while directing the reader to comprehensive reviews on studies concerning stem cells in the human breast (Petersen \& Polyak 2010, Visvader \& Stingl 2014). Importantly, we will address how studies on stem cells during normal murine mammary development have helped inform our understanding of breast cancer.

\section{Mammary stem cells in development}

The murine mammary gland anlage is established from the ventral ectoderm as a result of inductive influences from the underlying mesenchyme. This occurs during embryogenesis at E12.5, at which point the rudiment is stably committed to the mammary lineage. The mammary rudiment continues to invade into the fat pad precursor until a primitive branched structure exists at E18.5 (Veltmaat et al. 2003). This is accompanied by a concomitant expansion in the MaSC population termed fetal MaSCs (fMaSCs), which constitutes the earliest MaSC population (Spike et al. 2012). fMaSCs can be enriched using the $\mathrm{CD} 24^{\mathrm{hi}} \mathrm{CD} 49 \mathrm{f}^{\mathrm{hi}}$ cell surface protein marker profile and may presumably be the same pool of bipotent MaSCs $\left(\mathrm{K} 14^{+} / \mathrm{K}^{+}\right)$observed in multiple lineage-tracing studies (Fig. 1; Van Keymeulen et al. 2011, Rios et al. 2014). Interestingly, the gene expression signature of fMaSCs differed significantly from the adult CD29 ${ }^{\text {hi }} 24^{+}$MaSCs (aMaSCs), yet had the capacity to give rise to fully functional, morphologically normal mammary outgrowths upon transplantation. The discordance between the $\mathrm{fMaSC}$ and aMaSC gene signature could be partially attributed to the fact that fMaSCs are not yet restricted into basal and luminal lineages. This study also unveiled several reciprocal gene expression patterns in the embryonic bud and the fetal stromal environment further elucidating the paracrine interactions thought to occur early during mammary development. Furthermore, the enrichment of stem cells as measured by stem cell frequency upon limiting dilution transplantation was about fourfold higher using fMaSC markers as compared to aMaSCs ( ${ }^{*}$ Frequency $=1 / 14$ compared to $1 / 50$ in the aMaSC population in this study) (Spike et al. 2012).

The rudimentary branched mammary structure at birth remains seemingly dormant until the initiation of puberty at about 3 weeks of age. The spike in estrogen levels that accompanies puberty manifests in a burst of proliferation and resultant bulbous structures termed terminal end buds (TEBs) at the distal ends of the mammary ducts. The TEBs are thought to drive the growth and arborization of the ducts throughout the mammary fat pad as a consequence of resident cells undergoing several rounds of cell division (Hinck \& Silberstein 2005). The TEB is composed of a single outer layer of cap cells and underlying multilayered body cells that are the precursors to the adult mature $\mathrm{K}^{+} / \mathrm{K} 14^{+}$basal layer and $\mathrm{K}^{+} / \mathrm{K} 18^{+} / \mathrm{K} 19^{+}$luminal layer respectively. Interestingly, early studies also demonstrated that the rapidly dividing epithelial end bud structures in rats are the targets of dimethyl benzanthracene-mediated mammary carcinogenesis, emphasizing the importance of a deeper understanding of this developmental stage (Russo \& Russo 1980). A small proportion of cap cells have also been observed to migrate into the inner body cell layers and have long been hypothesized to be a potential pool of bipotent stem cells, i.e., cells capable of giving rise to both basal and luminal cells (Williams \& Daniel 1983). Based on the relatively undifferentiated ultrastructure of the cap cells in the TEB, these cells are a putative population of enriched MaSCs. Indeed, a stem cell-associated s-SHIP promoter-driven GFP reporter allowed specific isolation of the cap cell population that could efficiently repopulate fully functional mammary glands in a limiting dilution transplantation assay ( ${ }^{*}$ Frequency $=1 / 71$ in $\mathrm{s}$-SHIP ${ }^{+}$ aMaSCs compared to $1 / 333$ in the s-SHIP $^{-}$aMaSC population in this study. However, in this experiment, the comparative frequency to the total aMaSC population

Published by Bioscientifica Ltd. 
A

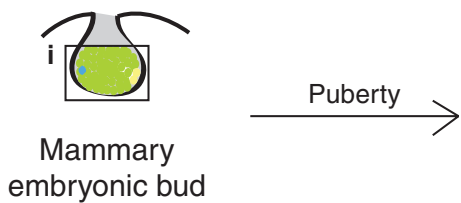

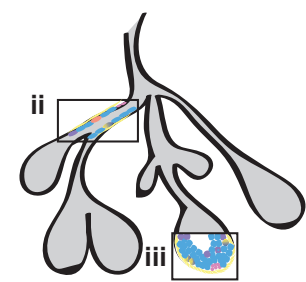

Mammary ducts with distal end buds
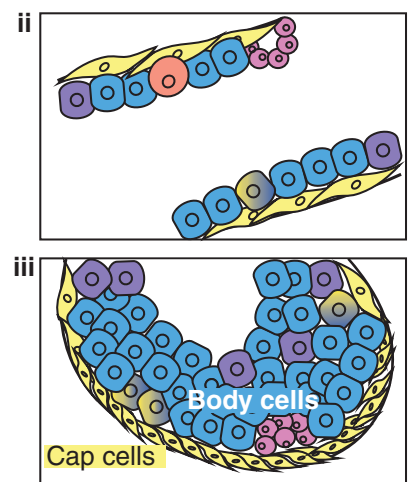

$\mathrm{K} 5 ; \mathrm{K} 14^{+}, \mathrm{Axin}^{+}, \mathrm{Procr}^{+}$,

aSMA $^{+}$basal bipotent progenitors and mature cells

Basal-luminal intermediate cell

$\mathrm{K}^{+}$, Elf5 ${ }^{+}$, Notch $1^{+}$, Notch $3^{+}$ luminal unipotent progenitors and mature $\mathrm{ER} \alpha, \mathrm{PR}-$ cells

$\mathrm{K}^{+}, \mathrm{ER} \alpha, \mathrm{PR}^{+}$mature luminal cell (unknown origin)

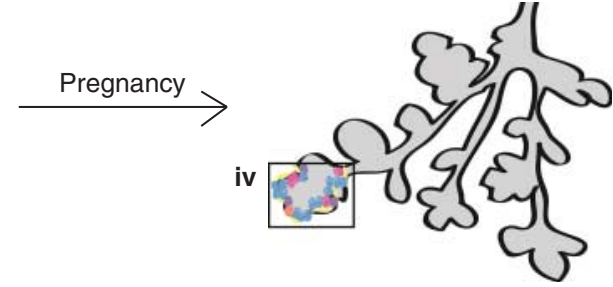

Mammary ducts with alveoli
$\mathrm{K} 8, \mathrm{~K} 18 / \mathrm{K} 5, \mathrm{~K} 14^{+}, \mathrm{Axin}^{+}$, (presumably fMaSCs)
(procr multipotent proger

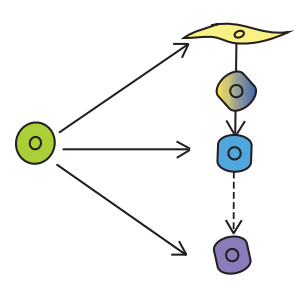

\section{Figure 1}

Schematic illustration of the mammary epithelial cell hierarchy in a developmental context. (A) This panel illustrates the three critical stages in the ontogeny of the mammary epithelium. (i) The mammary gland begins development as an invaginated bud in the embryo. Upon the onset of puberty, (iii) terminal end buds (TEBs) drive the rapid expansion of (ii) ductal structures through the fat in a proliferation-dependent manner. TEBs (iii) comprise an outer layer of cap cells and multilayered body cells that are thought to largely give rise to basal and luminal cells respectively. During pregnancy, (iv) the epithelium proliferates and expands to form grape-like clusters of alveoli that secrete milk during lactation. Magnified snapshots of the (i) embryonic bud, (ii) ductal, (iii) TEB and (iv) alveolar structures indicate the complex and rapidly dynamic cellular compositions during different stages of mammary development. (B) The cells observed spatially in their epithelial context in (A) are displayed based on their position in the epithelial stem cell hierarchy as gleaned from lineagetracing data. Multipotent progenitors in the embryonic bud differentiate to generate all the mature mammary lineages. In the adult, ducts comprise of basal and luminal lineages. Lineage-tracing data have identified cells in the basal compartment with bipotential capacity, i.e., the ability to give rise to both basal and luminal lineages. More recently, novel Notch $2^{+}$luminal populations were described whose origin and function remain ambiguous. Finally, studies in multiparous mice have identified long-lived progenitors termed parity-induced mammary epithelial cells (PI-MECs) that are capable of initiating multiple rounds of alveologenesis during repeated pregnancies. Dotted lines indicate hypothesized derivative cell lineages in the epithelial hierarchy. was not determined) (Bai \& Rohrschneider 2010). This population of cells was recently demonstrated to possess high canonical Wnt signaling activity, a hallmark of stem cells in multiple organs (Roarty et al. 2015). Intriguingly, a protein in the Par family of polarity regulators called Par3L was identified in cap cells in the TEB (and at luminal tight junctions) and found to be crucial for the maintenance of stem cells (Huo \& Macara 2014). Whether these polarity proteins have a secondary role in orienting the different planes of cell division observed in cap cells (Regan et al. 2013), similar to the role of the Par complex in Drosophila neuroblasts, remains unknown.

At the end of puberty, the TEBs disappear, resulting in the mature adult mammary gland, which comprises the epithelial skeleton upon which alveoli-like buds and alveoli form during the estrous cycle and pregnancy respectively. FACS allowed the identification and prospective isolation of aMaSCs based on their 
CD $24^{+}$CD $29^{\text {hi }} /$ CD $49 \mathrm{f}^{\text {hi }}$ cell surface marker profile (Shackleton et al. 2006, Stingl et al. 2006). This population of aMaSCs is transiently expanded upon progesterone exposure during the diestrus phase of each estrous cycle and efficiently repopulates the mammary gland in limiting dilution transplantation assays (Joshi et al. 2010). Additionally, the top 5\% most brightly stained CD $49 \mathrm{f}^{\text {hi }}$ cells are thought to further enrich for aMaSCs (Stingl et al. 2006). Based on the observation that the aMaSC population harbored label-retaining cells, RNA-seq for cell surface markers on the long-term label-retaining population revealed CD1d as a prospective marker of quiescent stem cells (dos Santos et al. 2013). When used in combination with the CD $24^{+} 29^{\text {hi }}$ basal/aMaSCs, CD1d was able to significantly enrich the stem cell frequency as scored by limiting dilution analysis ( ${ }^{*}$ Frequency $=1 / 8$ in $\mathrm{CD}_{1} \mathrm{~d}^{+}$aMaSCs compared to $1 / 44$ in the total aMaSC population in this study). Recently, Procr, a previously described $\mathrm{CD} 44^{+} \mathrm{CSC}$-associated protein (Shipitsin et al. 2007), has been identified as a Wnt pathway target and a novel aMaSC marker that also repopulates the mammary gland at a high frequency upon transplantation ${ }^{*}$ Frequency $=\sim 1 / 12$ in Procr $^{+}$aMaSCs compared to $1 / 69$ in the total aMaSC population in this study). Interestingly, these Procr $^{+}$cells have a low keratin profile and some epithelial-to-mesenchymal transition (EMT)-like properties. The Procr ${ }^{+}$stem cells appear to be cycling but do not overlap with the transient cap cell population, suggesting that they may comprise another non-quiescent subset of aMaSCs. Also of note is that Procr $^{+}$cells largely do not overlap with Axin2 ${ }^{+}$cells in the mammary gland, though both markers are canonical Wnt pathway targets, suggesting additional layers of complexity (Wang et al. 2014). Whether these $\mathrm{Procr}^{+}$cells constitute the progesterone-induced amplified aMaSC population remains unclear. Yet it is becoming increasingly apparent that multiple aMaSC populations might exist to carry out specific functions relating to the homeostatic and proliferative demands of the mammary gland.

Finally, alveologenesis and the priming of alveolar cells for milk production and secretion reflect pregnancyassociated changes in the mammary gland. There is an expansion in the MaSC population at mid-pregnancy that strikingly correlates with s-SHIP re-expression specifically in basal alveolar cells (Bai \& Rohrschneider 2010). These stem cells are distinct from the aMaSC population based on their gene expression signature and are thought to be poised for alveolar differentiation. Notably, a longlived population of alveolar parity induced-mammary epithelial cells (PI-MECs) is retained through gland remodeling post-pregnancy and is thought to initiate a new round of alveologenesis during subsequent pregnancies (Boulanger et al. 2005). Lineage tracing using an alveolar-specific whey acidic protein (WAP) promoterdriven Cre demonstrated that PI-MECs contribute to the luminal layer but only to the hormone receptor-negative cells through multiple pregnancies (Chang et al. 2014). This suggests the existence of separate pools of progenitor cells maintaining the basal and/or hormonal receptorpositive cells during pregnancy. Whether the existence of PI-MECs and the pregnancy expanded MaSC populations are coupled or independent remains an open question.

Thus, the mammary gland is thought to house multiple populations of stem cells that fulfill the requirement of self-renewal and differentiation into mature cell lineages. Do these stem cells exist in invariant stable states or do they exhibit plasticity induced by developmental cues, hormones and the microenvironment? The latter possibility has been suggested recently where a large percentage $(\sim 60 \%)$ of $\alpha \mathrm{SMA}^{+}$cells display stem cell capacity upon single-cell dissociation and assessment by colony formation and limiting dilution transplantation (Prater et al. 2014). Additionally, while some of the stem cell pools, e.g., fMaSCs, s-SHIP ${ }^{+}$cells and Procr $^{+}$cells (Bai \& Rohrschneider 2010, Spike et al. 2012, Wang et al. 2014) demonstrate active cell cycling dynamics, others such as $\mathrm{CD} \mathrm{d}^{+}$aMaSCs display label retention and are quiescent in vivo (dos Santos et al. 2013). Such a multiplicity of stem cell populations with different cycling dynamics has been observed in other organ systems (Li \& Clevers 2010), where a quiescent stem cell pool acts as a long-term reservoir that is co-opted following stress responses, e.g., wounding in the epidermis, whereas the proliferative pool is required to maintain normal tissue homeostasis. Whether the quiescent and rapidly cycling stem cell pools in the mammary gland are independently required or if they serve redundant functions remains shrouded in mystery. There is a pressing requirement for improved ex vivo models that recapitulate the entire gamut of mammary epithelial cell types, e.g., the organoid culture models developed for a number of other epithelial tissues (Sato et al. 2009), to better dissect these mammary population subtypes and their crosstalk. Efficient ex vivo models should be designed to help independently confirm the interpretation of differences in outgrowth efficiency observed in the transplantation assay. In its current form, the transplantation assay results in the same readout (i.e., impaired outgrowths) whether there is defective stem cell survival, decreased stem cell frequency, inability to recapitulate the stem cell niche and/or abnormal

Published by Bioscientifica Ltd. 
differentiation into derivative lineages and should therefore be interpreted with caution.

(*Note that it is not possible to directly compare absolute stem cell frequencies reported between different studies and laboratories, often performed in different mouse strains, to assess the relative purity of these enriched populations. Indeed, variations in cell surface marker expression, e.g., CD61, have been reported in different mouse strains (Shehata et al. 2012). This will require more stringent single cell analyses and direct comparisons in the same mouse strain.)

\section{Pathways regulating MaSCs}

The ovarian hormones estrogen and progesterone underlie many of the instructive cues guiding development and tissue homeostasis within the mammary gland (Brisken \& O'Malley 2010). Whether during bursts of proliferation in puberty and pregnancy, or simply during fluctuations within the estrous cycle, estrogen and progesterone enlist the assistance of multiple signaling pathways to regulate the coordinated efforts of the epithelial hierarchy during stages of active morphogenesis and maintenance. The mere fact that MaSCs are $\mathrm{ER} \alpha / \mathrm{PR}^{-}$implies the requirement of paracrine mechanisms for MaSC regulation by hormones (AsselinLabat et al. 2006). These paracrine mechanisms have long been appreciated, dating back to the discovery of $\mathrm{ER} \alpha / \mathrm{PR}^{+}$cells as the sensor cells necessary to relay proliferative cues to neighboring ER $\alpha / \mathrm{PR}^{-}$cells (Mallepell et al. 2006, Beleut et al. 2010), yet it remains unclear how certain pathways regulate an ever-changing epithelial landscape in the mammary gland.

One pathway touted as an indisputable regulator of self-renewal in stem cells is Wnt signaling (Clevers et al. 2014). Several studies throughout the years have identified multiple Wnt ligands in the mammary gland, characterized by spatiotemporal specific patterns of expression (Gavin \& McMahon 1992, Kouros-Mehr \& Werb 2006). MaSCs clearly possess active Wnt/ $\beta$-catenin-dependent signaling, as evidenced by Axin2 (Zeng \& Nusse 2010) and 7TCF/Lef reporter activity (Roarty et al. 2015). Axin2 ${ }^{+}$ stem cells additionally express higher levels of the Wnt co-receptors Lrp5 and Lrp6 (Zeng \& Nusse 2010), while ablation of Lrp5 disrupts MaSC function and basal cell number (Badders et al. 2009). Intriguingly, lineage-tracing studies using an Axin2-driven Cre line reveal stage-specific differences in lineage contributions by Axin $2^{+}$stem cells (van Amerongen et al. 2012). Although the precise function of individual Wnt proteins in vivo is still evolving, it is known that some Wnt proteins possess the ability to convey self-renewal signals to MaSCs by Wnt/ $\beta$-catenindependent signaling. The sustained activation of Wnt/ $\beta$-catenin signaling in vivo by MMTV-dependent control of $W n t 1$ or active- $\beta$-catenin ( $\Delta \mathrm{N}-\beta$-catenin) expression can expand stem and progenitor fractions, underpinning the influence of Wnt signaling on primitive epithelial cell populations in vivo (Incassati et al. 2010).

Initially recognized as a Wnt ligand downstream of progesterone signaling, Wnt4 has gained considerable attention with respect to MaSC regulation. Joshi et al. (2010) identified an increase in MaSC number and activity upon initiation of the luteal diestrus phase of the mouse estrous cycle, coinciding with elevated progesterone levels. Moreover, Wnt4 and RANKL expression were induced downstream of progesterone in the luminal compartment, implicating both as mediators of progesterone-regulated MaSC control (Asselin-Labat et al. 2010, Joshi et al. 2010). While RANKL has been shown to be an important paracrine mediator in the mouse and human mammary gland (Gonzalez-Suarez et al. 2010, Tanos et al. 2013), the conclusions of several studies conflict as to whether it plays a primary or secondary role. Recently, Rajaram et al. (2015) discovered the activation of Wnt/ $\beta$-catenin signaling in diestrus using an Axin2 $2^{+/ L a c Z}$ reporter model, with ablation of Wnt4, not RANKL, severely impairing the regenerative capacity of the mammary epithelium together with Wnt/ $\beta$-catenin activity, based on the serial transplantation of epithelial fragments. On the other hand, RANK signaling reinforced Wnt-responsiveness of mammary stem and progenitor cells through R-Spondin in a separate study (Joshi et al. 2015). Though slightly inconsistent, the above studies collectively provide evidence for an integrated RANKL/Wnt network downstream of progesterone, instrumental for proliferative and self-renewal cues within the mammary epithelium. Additionally, alternative Wnt/ $\beta$-catenin-independent ligands, Wnt5a and Wnt5b, can negatively regulate $\mathrm{Wnt} / \beta$-catenin signaling (Roarty et al. 2015), and Kessenbrock et al. (2013) identified an indirect role for the metalloproteinase MMP3 in the regulation of MaSCs by inactivating Wnt5b function, thus extending our understanding of Wnt pathway biology as it relates to microenvironmental regulation of MaSC dynamics. Other factors within the microenvironment, such as the tissue inhibitors of metalloproteinases (TIMPs), can also instruct decisions of MaSC fate (Jackson et al. 2015).

In collaboration with Wnt signaling, additional pathways also play an integral part in the establishment of cellular fate in the mammary gland. While the

Published by Bioscientifica Ltd. 
Wnt/ $\beta$-catenin-dependent pathway oversees MaSC instructive cues, the activity of Notch and Hippo pathways can tweak the ability of a MaSC to commit to a luminal fate. For instance, Pygo2, a histone methylation reader and $\mathrm{Wnt} / \beta$-catenin co-activator, can direct the balance of self-renewal Wnt signals with luminal-specific Notch signals in mammary epithelial lineage determination within the MaSC (Gu et al. 2013). Absence of Pygo2 shifts this balance toward a luminal-directed fate by favoring Notch activation. Additionally, absence of the Notch effector Cbf- 1 can expand the MaSC pool and regenerative potential of the mammary gland, where low levels of Cbf- 1 normally quell MaSC functions (Bouras et al. 2008). Given the link between Notch and aurora A kinase (AURKA) in mitotic spindle orientation in the TEB (Regan et al. 2013), Wnt and Notch could have a collaborative function in orientation of the spindle pole, thus influencing MaSC fate determination during puberty. With regard to Hippo signaling, the transcriptional co-activator TAZ interacts with components of the SWI/SNF complex to specify basal-specific gene expression, where loss of TAZ coerces basal cells down a luminal fate (Skibinski et al. 2014). Given that TAZ can mediate a subset of Wnt/ $\beta$-catenindependent transcriptional outputs, MaSC control likely requires a combination of Hippo and Wnt signaling, with Notch signaling initiating a luminal path of fate specification for the MaSC in the mouse mammary gland.

\section{Mammary epithelial cell hierarchy}

The mammary epithelium is a bilayered structure that comprises the cytokeratin $\mathrm{K}^{+} / \mathrm{K}_{1} 4^{+}$basal or myoepithelial cell layer and the $\mathrm{K}^{+} / \mathrm{K} 18^{+} / \mathrm{K} 19^{+}$luminal cell layer. The basal compartment is thought to house both the aMaSCs and basal cells in a continuum of differentiation. Therefore, caution should be employed when interpreting stem cell phenotypes, as they maybe secondary to a broader impairment of basal cells. In addition, basal cells have contractile abilities that help the pumping of milk during lactation. The luminal cells in the mammary gland consist of $\mathrm{ER} \alpha$ and PR-positive as well as -negative cells. A majority of the luminal progenitor cells are a subset of the $\mathrm{ER} \alpha / \mathrm{PR}^{-}$population and are thought to contain the alveolar progenitor subset (Fig. 1).

Hormonal cues are the harbingers of developmental changes in the mammary gland and orchestrate a series of paracrine interactions between epithelial and stromal cell types to elicit phenotypic changes in the mammary gland. Despite the presence of $\mathrm{ER} \alpha$ (Lemmen et al. 1999) and PR-positive cells in the embryonic mammary glands
(Ismail et al. 2002), hormone dependent morphological effects are primarily observed at and after the onset of puberty. $\mathrm{ER} \alpha^{-1-}$ mammary gland ducts fail to form TEBs and ramify in the fat pad (Mallepell et al. 2006). $\mathrm{PR}^{-1-}$ mammary epithelium shows a less drastic phenotype but displays a reduction in side branching and impaired alveologenesis. Elegant experiments performed using WT mammary epithelial cells mixed with $\mathrm{ER}^{-/-}$or $\mathrm{PR}^{-/-}$ (Brisken et al. 1998, Mallepell et al. 2006) mammary epithelial cells formed chimeric outgrowths that rescued the phenotypes initially observed in the absence of the WT cells. Importantly, these studies dissected out a paracrine mechanism in which hormones act on $\mathrm{ER} \alpha / \mathrm{PR}^{+}$cells, which then secrete growth factors such as Amphiregulin (estrogen effector), RANKL and Wnt4 (progesterone effectors) locally, causing their adjacent cells to proliferate (Brisken et al. 2000, Ciarloni et al. 2007, Beleut et al. 2010, Rajaram et al. 2015). Hormones induce downstream factors such as Wnt4 (Asselin-Labat et al. 2010) and R-spondin1 (Cai et al. 2014) that act on MaSCs, thus indirectly regulating stem cell activity. Additionally, progesterone has been implicated in inducing vast changes to the epigenome of the luminal cell compartment that may underlie this paracrine effect $(\mathrm{Pal}$ et al. 2013).

Several core regulators of the different mammary lineages have been identified. The transcription factor $\Delta \mathrm{Np63}$ is a master regulator of the basal/MaSC lineage that acts by potentiating Wnt signaling in this compartment (Chakrabarti et al. 2014). p63 ${ }^{+}$basal cells can additionally regulate secretion of Neuregulin1 and effect luminal progenitor differentiation and lactogenesis (Forster et al. 2014). p53 has also been ascribed the role of a negative regulator of the MaSC pool and modulates stem cell division dynamics by controlling the proportion of asymmetric cell division to symmetric cell division in vitro using mammosphere assays (Cicalese et al. 2009). A separate study observed an expansion in the basal and luminal MaSC population in TP53 null mice (Chiche et al. 2013). Whether this in vivo stem cell expansion is a direct consequence of increased symmetric cell divisions upon TP53 loss remains to be determined. Gata3 on the other hand is considered a master regulator of the mature mammary luminal lineage. Loss of Gata3 leads to the accumulation of $\mathrm{CD}^{+} 1^{+}$luminal progenitors (AsselinLabat et al. 2007). A similar accumulation of progenitors is also observed upon in tissues displaying a Brca1 loss of function mutation (Lim et al. 2009). Alveolar differentiation is regulated in part by the ETS family transcription factor Elf5 in a prolactin hormone-dependent manner

Published by Bioscientifica Ltd. 
(Oakes et al. 2008). Elf5 also seems to be a key regulator of basal to luminal cell fate decisions (Chakrabarti et al. 2012). At what point between gestation and puberty the $\mathrm{K}^{+} / \mathrm{K} 4^{+}$embryonic bud cells diverge into basal and luminal specific lineages with their distinct transcriptional machinery and acquire their characteristic Notch and Wnt signaling polarity remains an outstanding question.

\section{Lineage-tracing studies}

In an attempt to study MaSC pools and their resultant progeny in their in vivo unperturbed stem cell niches, mammary gland biology has relied heavily on genetic lineage-tracing studies. These elegant studies, more recently combined with high-resolution 3D microscopy techniques, have helped uncover the spatial and temporal dynamics that exist within the mammary epithelial hierarchy. For a detailed current review of lineage-tracing methods in the mammary gland, see Sale \& Pavelic (2015). Many lineage-tracing studies have utilized tamoxifeninducible models, however results should be interpreted with caution in light of the now well understood effects of the ER antagonist on mammary gland homeostasis (Rios et al. 2014, Shehata et al. 2014).

Several lines of evidence suggest that basal MaSCs (some $\mathrm{K}^{+}$cells, Procr $^{+}$cells) possess an inherent capacity for bipotency, i.e., they can act as precursors of both basal and luminal cells during different stages of development (Rios et al. 2014, Wang et al. 2014). This ability is particularly striking in the embryonic bud and during pregnancy (Axin $2^{+}$basal cells) whereas mammary tissue homeostasis in the adult primarily relies on unipotent stem cell division $\left(\mathrm{K}^{+}, \mathrm{K}^{+} 4^{+}, \mathrm{aSMA}^{+}\right.$basal cells) (Van Keymeulen et al. 2011, van Amerongen et al. 2012, Prater et al. 2014). Certainly, in the case of both $\operatorname{Lgr}^{+}$(De Visser et al. 2012) and Axin2 ${ }^{+}$MaSCs (van Amerongen et al. 2012), a stage-dependent influence on the lineage contribution by these particular MaSC populations exists. Notch2 receptor-driven Cre-based lineage tracing helped identify a novel putative cell population distributed periodically throughout the luminal mammary epithelial compartment that are hypothesized to potentially mark the epithelial branch points, but it is unclear if these are actually live cells that are detected since they do not conform to known mammalian cell or nuclear sizes (Šale et al. 2013). Interestingly, luminal progenitor cells marked by an Elf5-driven Cre are unipotent in their ability to generate the luminal population alone (Rios et al. 2014). Lineage tracing using WAP-driven Cre recombinase identified PI-MECs that are sustained through multiple rounds of pregnancy and repopulate alveoli in subsequent pregnancies with $\mathrm{ER} \alpha / \mathrm{PR}^{-}$cells (Boulanger et al. 2005). Indeed, a recent study using a Notch1 receptor-driven Cre that marks $\mathrm{ER} \alpha / \mathrm{PR}^{-}$luminal progenitors in the adult mammary gland only gives rise to $\mathrm{ER} \alpha / \mathrm{PR}^{-}$differentiated luminal and alveolar cells (Rodilla et al. 2015). The source and turnover of $\mathrm{ER} \alpha / \mathrm{PR}^{+}$cells remains hitherto unknown. Thus, lineage tracing has helped answer some very critical questions regarding the mammary epithelial cell hierarchy but has also generated intriguing new questions to be addressed (Fig. 1).

\section{Cell(s) of origin in breast cancer}

While genetic lineage-tracing studies have helped refine our understanding of mammary epithelial hierarchies, the broader question that still exists is which of these cell types can serve as the cell or cells of origin in the different subtypes of breast cancer. For an excellent recent review, see Visvader \& Stingl (2014). Several instances of basal bipotent stem cells giving rise to luminal cells have now been described; however, the reverse process, i.e., $\mathrm{K}^{+}$ luminal cells giving rise to basal cells has never been observed in vivo in the normal mammary gland. Alterations in the tumor suppressor Brca1 were observed to result in abnormal luminal to basal differentiation (Proia et al. 2011). Elegant studies have also shown that exogenous introduction of Slug alone could confer differentiated luminal cells with a basal cell fate. In addition, introduction of Slug together with Sox9 converted differentiated luminal cells into basal MaSCs with long-term reconstitution ability (Guo et al. 2012). Additionally, a recent study using retroviruses to target Polyoma middle $\mathrm{T}$ and Her2 oncogenes specifically to the luminal epithelial compartment demonstrated unequivocal luminal to basal transdifferentiation upon oncogenic insult (Hein et al. 2015). Along the same lines, acquiring properties of EMT reprograms cells to a more stem-like state (Mani et al. 2008). Could such a transcriptional network be epigenetically favored during tumorigenesis? Alternatively, could basal cells increase their usage of bipotent cell division at the cost of unipotent cell divisions that are prevalent during mammary tissue homeostasis to amplify a progenitor pool that contributes to tumorigenesis? Is oncogeneinduced transdifferentiation of the luminal cells alone sufficient to explain the plasticity and heterogeneity observed in breast cancers?

The basal-like subtype of breast cancer is often triplenegative i.e., lacking $\mathrm{ER} \alpha, \mathrm{PR}$ and amplified Her2 and

Published by Bioscientifica Ltd 
expresses basal cell markers (e.g., K5, K14, P-cadherin and Id4) (Vieira et al. 2012, Prat et al. 2013). This correlates with the profile in basal MaSCs, which were therefore intuitively thought to be a potential cell of origin for the basal-like tumor subtype. A model of Brca1 mutant basal tumors wherein Brca1 and p53 were altered in the luminal or basal cells alone using lineage specific Cre recombinases was employed to address this question. These studies showed that Brca1 and p53 conditional alterations in the luminal compartment reproduced the histogenesis of basal-like tumors more accurately than the same mutations in the basal compartment (Molyneux et al. 2010). These data combined with the observation that there is an expansion in the luminal progenitor pool upon Brca1 loss suggests, but does not prove in the absence of direct lineage-tracing studies that luminal progenitors are likely to be the cell of origin for Brca1 mediated basal-like tumors (Lim et al. 2009). Another study focused on the cell of origin of the hormone receptor-negative pregnancy-associated breast cancer. The model utilized an RCAS retrovirus to target Her2 specifically in cells expressing the receptor for the retrovirus in $\mathrm{WAP}^{+}$ alveolar cells (Haricharan et al. 2013). The resultant tumors histologically resembled pregnancy-associated breast cancers and confirmed that alveolar luminal cells (potentially PI-MECs) could act as the cellular origin for this tumor. This latter model also has significant advantages over genetically engineered mouse models (GEMMs), as targeted mutations to a handful of cells parallels tumorigenesis in humans better as compared to GEMMs where large swathes of cells are affected that may bias results.

Given the multitude of lineage-tracing models that have shed light on normal mammary gland development, the elucidation of the cells of origin for breast cancer subtypes and the effect of cell-specific alterations in critical regulatory pathways is in short order. However, one caveat is that these studies will all be performed in GEMMs and the conclusions from these studies will still be inferential with respect to the cell of origin for the different human breast cancer subtypes.

\section{Breast CSCs}

Breast tumors show a great deal of intertumoral heterogeneity and are classified into several subsets with varied patient outcomes and implications for treatment. One model that has been used to explain this heterogeneity suggests that an epithelial hierarchy akin to that observed in the normal mammary gland exists in tumors.
This model places a cell described as a CSC or tumorinitiating cell, with self-renewal and differentiation abilities, on top of a hierarchy of cells that forms the tumor bulk. These CSCs have the ability to seed new tumors upon transplantation at limiting dilutions and can also be grown as mammospheres. CSCs are additionally proposed to be slow-dividing or quiescent (Pece et al. 2010), which allows them a means to escape chemotherapy and seed tumor recurrence. This idea is cemented by the correlation that basal-like and claudin-low breast cancer subtypes that are often refractory to conventional therapy typically display an undifferentiated, stem cellenriched signature (Prat \& Perou 2010). The simplistic assumption is that targeting this CSC pool along with standard-of-care treatments may thus eliminate the tumor and the source of tumor recurrence.

The first clues suggesting the existence of CSCs came from studies by Al-Hajj et al. (2003) demonstrating that human breast cancer cells grown as xenografts contain a subset of $\mathrm{CD} 44^{+} \mathrm{CD} 24^{-}$cells with increased tumorigenic capacity when compared to the remaining population. Additionally, aldehyde dehydrogenase (ALDH) has been identified as a potential marker for human CSCs (Ginestier et al. 2007). Pertinently, a recent study shows that the $\mathrm{CD} 44^{+} \mathrm{CD} 24^{-}$cells are distinct from the $\mathrm{ALDH}^{+} \mathrm{CSCs}$ with the former population representing a quiescent, mesenchymal-like population and the latter representing a cycling, epithelial-like CSC population (Liu et al. 2014). Studies using mouse-derived tumors identified different surface markers e.g., CD29 ${ }^{\text {hi }} \mathrm{CD} 24^{+}$for CSCs in TP53 null tumor models (Zhang et al. 2008). These CSCs displayed resistance to radiotherapy and resulted in a model for combinatorial therapy using radiotherapy in conjunction with an Akt inhibitor that decreased survival and inhibited the Wnt/ $\beta$-catenin pathway. These results suggest that targeting resistant CSCs in combination with standard therapies may have value (Zhang et al. 2010). In other models, such as in the MMTV-Wnt1 model, the thymocyte antigen Thy $1^{+} \mathrm{CD} 24^{+}$population enriches for CSCs (Cho et al. 2008). However, this seems to contrast with a recent study demonstrating that MMTV-Wnt1 basal-like tumor growth is strictly dependent on a luminal source of Wnt1 (Cleary et al. 2014). One possibility that can explain this apparent discrepancy is that CSCs can divide asymmetrically to give rise to the luminal Wnt1-supporting population, analogous to the transplantation of a single normal MaSC that engenders its own niche. Furthermore, critical regulators of the basal/MaSC populations during normal development, such as $\Delta \mathrm{Np} 63$, regulate CSCs through Hedgehog- (Maria et al. 2015) and

Published by Bioscientifica Ltd. 
Wnt-dependent pathways (Chakrabarti et al. 2014). The lack of consistent markers of CSCs in different models has catalyzed an alternative approach, utilizing pathwayspecific reporters to identify a subset of cells with CSC-like properties. This method has successfully been utilized in some tumors using Wnt- (Zhang et al. 2010) and Stat3specific reporters (Wei et al. 2014). Particularly using the Wnt pathway reporter, CSCs were identified that are resistant to radiotherapy through efficient DNA damage repair machinery (Zhang et al. 2010). Other studies have focused on integrin signaling. Inhibition of focal adhesion kinase, which mediates integrin signaling, results in a decline in CSCs (Luo et al. 2013). Several other pathways such as Notch and TGF $\beta$ are actively being investigated. A multitude of targeted therapies are being developed in an attempt to specifically eliminate the CSC population, including Wnt (Blagodatski et al. 2014) and integrin antagonists (Goodman \& Picard 2012). These therapeutic strategies rely on the presence of an immutable CSC target, whereas the emerging evidence suggests that this may be an oversimplification.

The CSC state has been intertwined with the acquisition of EMT properties. This links CSCs with metastasis, thus creating additional challenges for the course of therapy. Human mammary epithelial cells undergoing EMT acquire CSC properties and similar to the normal mammary gland (Mani et al. 2008), exogenous expression of EMT inducers can induce plasticity in the non-CSC pool allowing them to acquire CSC-like properties (Hollier et al. 2013). However, EMT is not absolutely associated with the gain of stem cell properties. A deeper understanding of the dynamics and regulation of these processes will help inform treatment strategies in the future. The CSC hypothesis is now more complex than the simple linear model with a CSC situated on top of the hierarchy. One of the biggest challenges to this model is the issue of plasticity, potentially related to dynamic EMT processes. Several studies have now demonstrated that the non-CSCs can acquire CSC-like properties either as a result of genetic mutations resulting in dedifferentiation (Chaffer et al. 2011) or in a microenvironment-dependent manner (Iliopoulos et al. 2011, Malanchi et al. 2012). The evolving model of tumorigenesis now departs from this single hierarchical model and incorporates a multi-clonal heterogenous perspective with continual crosstalk between the different populations. Thus, the revised CSC model is not mutually exclusive of earlier models of clonal evolution, and hypothesizes that there may be more than a single CSC population.

\section{Heterogeneity of breast cancers: lessons from the mammary epithelial hierarchy}

The emergence of high-throughput technologies has helped classify breast cancers into at least five molecular subtypes based on the analysis of gene expression patterns among individual tumors, paving a new path in the subclassification of breast cancers and the immense heterogeneity present within them (Perou et al. 2000, Sorlie et al. 2001). These intrinsic subtypes, commonly referred to as Luminal A, Luminal B, HER2-enriched, basal-like, claudin-low and normal breast-like, are also recapitulated in several GEMMs, highlighting their utility in providing an additional toolbox for unraveling the complexities surrounding tumor heterogeneity (Herschkowitz et al. 2007, Pfefferle et al. 2013). The convergence of developmental and cancer biology fields occurred upon the identification of similarities between the transcriptional profiles of the intrinsic subtypes and individual epithelial subpopulations of the normal breast (Prat \& Perou 2010). Intriguingly, the luminal progenitor fraction of the normal breast epithelium exhibited striking similarities in gene expression to that of the basal-like subtype of breast cancers (Lim et al. 2009), indicating that the luminal progenitor might be the cell-of-origin for BRCA1 mutant carriers (Molyneux et al. 2010). The aMaSC signature, on the other hand, correlated with the claudinlow and normal breast-like subtypes, while the mature luminal signature was closely associated with Luminal A and B subtypes. The overlap in aMaSC and claudin-low signatures corroborates other studies that demonstrate mesenchymal features of this particular subtype (i.e., lack of claudins and tight junctions) and the fact that an EMT confers the transition of a cell to an undifferentiated stemlike state (Mani et al. 2008, Taube et al. 2010). While most studies rely on the alignment of the adult human epithelial hierarchy to breast cancer subtype, Spike et al. (2012) identified a signature from the isolation of the murine embryonic MaSCs that showed significant enrichment of the fMaSC signature in basal-like and Her2 ${ }^{+}$ tumors. A separate study also demonstrated that embryonic mammary signature subsets were enriched in basal-like breast cancers and those of BRCA1-null murine tumors (Zvelebil et al. 2013). Collectively, these data may implicate the potential cell of origin for a particular subtype based upon the association with a lineagerestricted gene signature. Alternatively, they may simply reflect the differentiation status of a given tumor, which correlates with a defined epithelial subpopulation within the hierarchy. Future lineage-tracing studies will likely

Published by Bioscientifica Ltd. 
resolve these outstanding questions. Nonetheless, the identification of subtype specificity mirroring the normal breast epithelial cell hierarchy is an intriguing correlation.

Aside from the molecular signatures of epithelial cell types instructing the biology and heterogeneity present within breast cancers, these signatures have potential clinical applications with respect to breast cancer etiology, prognostic capabilities and therapeutic insights. For instance, Pfefferle et al. identified consensus mouse and human signatures across multiple independent datasets and compiled 'enriched' and 'refined' signatures of the epithelial subpopulations to determine whether certain characteristics derived from the normal epithelial hierarchy could predict a pathologically complete response (pCR) of breast cancer patients to neoadjuvant chemotherapy (Pfefferle et al. 2015). Indeed, both 'refined' LumProg-HsEnriched signatures and one 'refined' fMaSCMmEnriched signature were capable of predicting pCR across all breast cancer patients analyzed. Additionally, the prognostic application of a different aMaSC signature derived from FACS-sorted mouse epithelial cells on the basis of $\mathrm{CD}_{2} 4^{+}$lowSca $1^{-} \mathrm{CD} 49 \mathrm{f}^{\text {high }} \mathrm{C}-\mathrm{Kit}^{-}$, was used to predict the likelihood of triple-negative breast cancers (TNBCs) to metastasize (Soady et al. 2015). Unlike Pfefferle et al., this aMaSC signature was enriched in the normal-like instead of claudin-low subtype, suggestive of differences present within the aMaSC signatures derived. Although not all lineage-restricted epithelial gene expression patterns possess prognostic capabilities, signatures defining the aMaSC-associated claudin-low group were enriched in residual tumors following either endocrine therapy or chemotherapy in the neoadjuvant setting, implying that resistant disease may involve an EMT-like aMaSC/ claudin-low population exhibiting less differentiated characteristics (Creighton et al. 2009). Collectively, such studies emphasize the value of understanding the normal developmental hierarchy to provide a foundation for unraveling subtype specificity and heterogeneity in breast cancers.

The mammary epithelial hierarchy can inform on many aspects of subtype specificity (i.e., intertumoral heterogeneity); however, the transcriptomic profiles of breast cancers fail to take into account the intratumoral heterogeneity present within a given tumor. With the advent of massive parallel sequencing, the heterogeneous landscape present within tumors can be interrogated with greater resolution (Banerji et al. 2012, Ellis et al. 2012, Shah et al. 2012, Stephens et al. 2012, TCGA 2012). For instance, from a subtype-specific stance, basal-like tumors possess a transcriptional signature similar to the luminal progenitor population of the normal hierarchy (Lim et al. 2009); however, basal-like tumors harbor a greater mutational repertoire and intratumoral heterogeneity relative to non-basal-like tumors within TNBCs (Shah et al. 2012), inferring an inherently more complex tumor architecture among the basal-like subtype. Aside from the mutational repertoire and identification of driver and passenger mutations, an outstanding question lies in how mosaic networks of cells, likely representing some degree of hierarchical organization, cooperate within a given tumor. Thus, investigation of the heterogeneous cell populations present, along with the pathways regulating these, is another approach to identify and target specific cell clones. Recently, Cleary et al. (2014), discovered interclonal cooperation between Hras-mutant basal cells and Wnt1-secreting luminal cells of the MMTV-Wnt1 transgenic model, suggesting that even cells with inferior fitness can provide a supportive role in an ever-changing tumor landscape. Along the same lines, in a TP53null transplantable murine model, which accurately reflects the heterogeneity and subtype-specificity of human breast cancers (Herschkowitz et al. 2012), mesenchymal-like niche cells and tumor-initiating cells were found to cooperate within a diverse cellular landscape, where the niche factors Wnt2 and CXCL12 were secreted by the mesenchymal cells and required by the tumor-initiating cells to sustain tumor growth (Zhang et al. 2015). Collectively, these data highlight the importance of not only identifying the cellular constituents within a given tumor, but also the signaling pathways required by specific cell populations to propagate the inherent heterogeneity observed. Unraveling this complexity may provide new insights into the mechanisms driving metastatic behavior of particular subpopulations and the ability of some of these subpopulations to resist therapy.

\section{Discussion}

Progress over the last decades in gathering a nuanced understanding of mammary gland biology has greatly honed our research approach to tackle the challenges of breast cancer. Markers of different epithelial subpopulations and stem cells are continually being refined. Notwithstanding, use of these markers in a lineage-tracing setting would allow us a window into early tumorigenesis that may prove essential to our understanding of the cellular dynamics in tumors. Additionally, the identification of pathway-specific regulators of these subpopulations could help provide an opportunity to gain a better grasp of potential mediators inter- and intratumoral

Published by Bioscientifica Ltd. 
heterogeneity among breast cancers. Importantly, as the evidence emerges for multiple clonal populations in tumors that mutually communicate and depend on each other, similar to the heterotypic interactions in the normal mammary gland, an exciting prospect is that targeting this critical communication would starve the interacting clones and thus impede tumor progression. Moving forward, this crosstalk may partially be deconstructed based on our understanding of the paracrine mechanisms that orchestrate normal homeostasis. Intrinsic to this problem is also determining the fitness of several combinatorial clones and if specific clonal populations are selected for during metastasis or post-treatment. A number of outstanding questions remain to be addressed.

1) What intrinsic and extrinsic cues specify a quiescent versus a cycling MaSC fate? How do these stem cell pools communicate? Are there similar stem cell pools in tumors?

2) How are the hormone receptor-positive cells derived and patterned during development?

3) How does spatial distribution of the different MaSC populations and other cells of the hierarchy contribute to normal development? Are cellular hierarchies organized in a spatial manner within breast cancers?

4) What is the extent of plasticity among the different epithelial subsets in the mammary gland, i.e., can cells transiently acquire MaSC properties or functionally differentiated characteristics based on developmental stage and the hormonal milieu?

5) Do the different mutations and/or cells of origin observed in breast cancer subtypes specify fitness in a handful of clones in heterogeneous tumors? Do these clones evolve stochastically or coordinately as an ecosystem?

6) How does the heterogeneous landscape of a metastasis relate to that observed in the primary tumor? Are these differences primarily due to genetic selection or epigenetic regulation by microenvironmental pressures at the secondary site?

\section{Declaration of interest}

The authors declare that there is no conflict of interest that could be perceived as prejudicing the impartiality of this review.

\section{Funding}

These studies were supported by grant CA16303 from the National Cancer Institute. A Sreekumar is supported by the Baylor College of Medicine Comprehensive Training Program grant RP140102 from CPRIT.
We apologize to those investigators whose work we were unable to cite due to space limitations.

\section{Acknowledgements}

The authors would like to thank Dr Michael Toneff for his critical reading of this manuscript.

\section{References}

Al-Hajj M, Wicha MS, Benito-Hernandez A, Morrison SJ \& Clarke MF 2003 Prospective identification of tumorigenic breast cancer cells. PNAS 100 3983-3988. (doi:10.1073/pnas.0530291100)

van Amerongen R, Bowman AN \& Nusse R 2012 Developmental stage and time dictate the fate of $\mathrm{Wnt} / \beta$-catenin-responsive stem cells in the mammary gland. Cell Stem Cell 11 387-400. (doi:10.1016/j.stem.2012. 05.023) (doi:10.1038/sj.onc.1208185)

Asselin-Labat M-L, Shackleton M, Stingl J, Vaillant F, Forrest NC, Eaves CJ, Visvader JE \& Lindeman GJ 2006 Steroid hormone receptor status of mouse mammary stem cells. Journal of the National Cancer Institute 98 1011-1014. (doi:10.1093/jnci/djj267)

Asselin-Labat M-L, Sutherland KD, Barker H, Thomas R, Shackleton M, Forrest NC, Hartley L, Robb L, Grosveld FG, van der Wees J et al. 2007 Gata-3 is an essential regulator of mammary-gland morphogenesis and luminal-cell differentiation. Nature Cell Biology 9 201-209. (doi:10.1038/ncb1530)

Asselin-Labat M-L, Vaillant F, Sheridan JM, Pal B, Wu D, Simpson ER, Yasuda H, Smyth GK, Martin TJ, Lindeman GJ et al. 2010 Control of mammary stem cell function by steroid hormone signalling. Nature 465 798-802. (doi:10.1038/nature09027)

Badders NM, Goel S, Clark RJ, Klos KS, Kim S, Bafico A, Lindvall C, Williams BO \& Alexander CM 2009 The Wnt receptor, Lrp5, is expressed by mouse mammary stem cells and is required to maintain the basal lineage. PLoS ONE 4 e6594. (doi:10.1371/journal.pone.0006594)

Bai L \& Rohrschneider LR 2010 s-SHIP promoter expression marks activated stem cells in developing mouse mammary tissue. Genes and Development 24 1882-1892. (doi:10.1101/gad.1932810)

Banerji S, Cibulskis K, Rangel-Escareno C, Brown KK, Carter SL, Frederick AM, Lawrence MS, Sivachenko AY, Sougnez C, Zou L et al. 2012 Sequence analysis of mutations and translocations across breast cancer subtypes. Nature 486 405-409. (doi:10.1038/nature11154)

Beleut M, Rajaram RD, Caikovski M, Ayyanan A, Germano D, Choi Y, Schneider P \& Brisken C 2010 Two distinct mechanisms underlie progesterone-induced proliferation in the mammary gland. PNAS $\mathbf{1 0 7}$ 2989-2994. (doi:10.1073/pnas.0915148107)

Blagodatski A, Poteryaev D \& Katanaev VL 2014 Targeting the Wnt pathways for therapies. Molecular and Cellular Therapies 228. (doi:10.1186/2052-8426-2-28)

Bonnet D \& Dick JE 1997 Human acute myeloid leukemia is organized as a hierarchy that originates from a primitive hematopoietic cell. Nature Medicine 3 730-737. (doi:10.1038/nm0797-730)

Boulanger CA, Wagner K-U \& Smith GH 2005 Parity-induced mouse mammary epithelial cells are pluripotent, self-renewing and sensitive to TGF- $\beta 1$ expression. Oncogene 24 552-560. (doi:10.1038/sj.onc.1208185)

Bouras T, Pal B, Vaillant F, Harburg G, Asselin-Labat ML, Oakes SR, Lindeman GJ \& Visvader JE 2008 Notch signaling regulates mammary stem cell function and luminal cell-fate commitment. Cell Stem Cell $\mathbf{3}$ 429-441. (doi:10.1016/j.stem.2008.08.001)

Brisken C \& O'Malley B 2010 Hormone action in the mammary gland. Cold Spring Harbor Perspectives in Biology 2 a003178. (doi:10.1101/cshperspect.a003178)

Brisken C, Park S, Vass T, Lydon JP, O’Malley BW \& Weinberg RA 1998 A paracrine role for the epithelial progesterone receptor in mammary 
gland development. PNAS 95 5076-5081. (doi:10.1073/pnas.95.9. 5076)

Brisken C, Heineman A, Chavarria T, Elenbaas B, Tan J, Dey SK, Mcmahon JA, Mcmahon AP \& Weinberg RA 2000 Essential function of Wnt-4 in mammary gland development downstream of progesterone signaling. Genes and Development 14 650-654. (doi:10.1101/gad.14.6.650)

Cai C, Yu QC, Jiang W, Liu W, Song W, Yu H, Zhang L, Yang Y \& Zeng YA 2014 R-spondin 1 is a novel hormone mediator for mammary stem cell self-renewal. Genes and Development 28 2205-2218. (doi:10.1101/gad. 245142.114)

Chaffer CL, Brueckmann I, Scheel C, Kaestli AJ, Wiggins PA, Rodrigues LO, Brooks M, Reinhardt F, Su Y, Polyak K et al. 2011 Normal and neoplastic nonstem cells can spontaneously convert to a stem-like state. PNAS $\mathbf{1 0 8}$ 7950-7955. (doi:10.1073/pnas.1102454108)

Chakrabarti R, Wei Y, Romano RA, DeCoste C, Kang Y \& Sinha S 2012 Elf5 regulates mammary gland stem/progenitor cell fate by influencing notch signaling. Stem Cells 30 1496-1508. (doi:10.1002/stem.1112)

Chakrabarti R, Wei Y, Hwang J, Hang X, Andres Blanco M, Choudhury A, Tiede B, Romano R-A, DeCoste C, Mercatali L et al. 2014 DNp63 promotes stem cell activity in mammary gland development and basallike breast cancer by enhancing Fzd7 expression and Wnt signalling. Nature Cell Biology 16 1004-1015. (doi:10.1038/ncb3040)

Chang TH-T, Kunasegaran K, Tarulli GA, De Silva D, Voorhoeve PM \& Pietersen AM 2014 New insights into lineage restriction of mammary gland epithelium using parity-identified mammary epithelial cells. Breast Cancer Research 16 R1. (doi:10.1186/bcr3593)

Chiche A, Moumen M, Petit V, Jonkers J, Medina D, Deugnier M-A Faraldo MM \& Glukhova MA 2013 Somatic loss of p53 leads to stem/progenitor cell amplification in both mammary epithelial compartments, basal and luminal. Stem Cells 31 1857-1867. (doi:10.1002/stem.1429)

Cho RW, Wang X, Diehn M, Shedden K, Chen GY, Sherlock G, Gurney A, Lewicki J \& Clarke MF 2008 Isolation and molecular characterization of cancer stem cells in MMTV-Wnt-1 murine breast tumors. Stem Cells 26 364-371. (doi:10.1634/stemcells.2007-0440)

Ciarloni L, Mallepell S \& Brisken C 2007 Amphiregulin is an essential mediator of estrogen receptor $\alpha$ function in mammary gland development. PNAS 104 5455-5460. (doi:10.1073/pnas.0611647104)

Cicalese A, Bonizzi G, Pasi CE, Faretta M, Ronzoni S, Giulini B, Brisken C, Minucci S, Di Fiore PP \& Pelicci PG 2009 The tumor suppressor p53 regulates polarity of self-renewing divisions in mammary stem cells. Cell 138 1083-1095. (doi:10.1016/j.cell.2009.06.048)

Clarke RB, Howell A, Potten CS \& Anderson E 1997 Dissociation between steroid receptor expression and cell proliferation in the human breast. Cancer Research $\mathbf{5 7}$ 4987-4991.

Cleary AS, Leonard TL, Gestl SA \& Gunther EJ 2014 Tumour cell heterogeneity maintained by cooperating subclones in Wnt-driven mammary cancers. Nature 508 113-117. (doi:10.1038/nature13187)

Clevers H, Loh KM \& Nusse R 2014 Stem cell signaling. An integral program for tissue renewal and regeneration: Wnt signaling and stem cell control. Science 346 1248012. (doi:10.1126/science.1248012)

Creighton CJ, Li X, Landis M, Dixon JM, Neumeister VM, Sjolund A, Rimm DL, Wong H, Rodriguez A, Herschkowitz JI et al. 2009 Residual breast cancers after conventional therapy display mesenchymal as well as tumor-initiating features. PNAS 106 13820-13825. (doi:10.1073/ pnas.0905718106)

Daniel CW 1975 Regulation of cell division in aging mouse mammary epithelium. Advances in Experimental Medicine and Biology 61 1-19.

Daniel CW, Aidells BD, Medina D \& Faulkin LJ Jr 1975 Unlimited division potential of precancerous mouse mammary cells after spontaneous or carcinogen-induced transformation. Federation Proceedings 34 64-67.

Deome KB, Faulkin LJ Jr, Bern HA \& Blair PB 1959 Development of mammary tumors from hyperplastic alveolar nodules transplanted into gland-free mammary fat pads of female C3H mice. Cancer Research 19 515-520.

De Visser KE, Ciampricotti M, Michalak EM, Tan DWM, Speksnijder EN, Hau CS, Clevers H, Barker N \& Jonkers J 2012 Developmental stage-specific contribution of LGR5 + cells to basal and luminal epithelial lineages in the postnatal mammary gland. Journal of Pathology 228 300-309. (doi:10.1002/path.4096)

Dontu G, Abdallah WM, Foley JM, Jackson KW, Clarke MF, Kawamura MJ \& Wicha MS 2003 In vitro propagation and transcriptional profiling of human mammary stem/progenitor cells. Genes and Development $\mathbf{1 7}$ 1253-1270. (doi:10.1101/gad.1061803)

Dos Santos CO, Rebbeck C, Rozhkova E, Valentine A, Samuels A, Kadiri LR, Osten P, Harris EY, Uren PJ, Smith AD et al. 2013 Molecular hierarchy of mammary differentiation yields refined markers of mammary stem cells. PNAS 110 1-8. (doi:10.1073/pnas.1303919110)

Eirew P, Stingl J, Raouf A, Turashvili G, Aparicio S, Emerman JT \& Eaves CJ 2008 A method for quantifying normal human mammary epithelial stem cells with in vivo regenerative ability. Nature Medicine $\mathbf{1 4}$ 1384-1389. (doi:10.1038/nm.1791)

Ellis MJ, Ding L, Shen D, Luo J, Suman VJ, Wallis JW, Van Tine BA, Hoog J, Goiffon RJ, Goldstein TC et al. 2012 Whole-genome analysis informs breast cancer response to aromatase inhibition. Nature 486 353-360. (doi:10.1038/nature11143)

Forster N, Saladi S, vanBragt M, Sfondouris M, Jones F, Li Z \& Ellisen L 2014 Basal cell signaling by p63 controls luminal progenitor function and lactation via NRG1. Developmental Cell 28 147-160. (doi:10.1016/j. devcel.2013.11.019)

Gavin BJ \& McMahon AP 1992 Differential regulation of the Wnt gene family during pregnancy and lactation suggests a role in postnatal development of the mammary gland. Molecular and Cellular Biology 12 2418-2423. (doi:10.1128/MCB.12.5.2418)

Ginestier C, Hur MH, Charafe-Jauffret E, Monville F, Dutcher J, Brown M, Jacquemier J, Viens P, Kleer CG, Liu S et al. 2007 ALDH1 is a marker of normal and malignant human mammary stem cells and a predictor of poor clinical outcome. Cell Stem Cell 1 555-567. (doi:10.1016/j.stem. 2007.08.014)

Gonzalez-Suarez E, Jacob AP, Jones J, Miller R, Roudier-Meyer MP, Erwert R, Pinkas J, Branstetter D \& Dougall WC 2010 RANK ligand mediates progestin-induced mammary epithelial proliferation and carcinogenesis. Nature 468 103-107. (doi:10.1038/nature09495)

Goodman SL \& Picard M 2012 Integrins as therapeutic targets. Trends in Pharmacological Sciences 33 405-412. (doi:10.1016/j.tips.2012.04.002)

Gu B, Watanabe K, Sun P, Fallahi M \& Dai X 2013 Chromatin effector Pygo2 mediates Wnt-notch crosstalk to suppress luminal/alveolar potential of mammary stem and basal cells. Cell Stem Cell 13 48-61. (doi:10.1016/j. stem.2013.04.012)

Guo W, Keckesova Z, Donaher JL, Shibue T, Tischler V, Reinhardt F, Itzkovitz S, Noske A, Zürrer-Härdi U, Bell G et al. 2012 Slug and Sox9 cooperatively determine the mammary stem cell state. Cell $\mathbf{1 4 8}$ 1015-1028. (doi:10.1016/j.cell.2012.02.008)

Haricharan S, Hein SM, Dong J, Toneff MJ, Aina OH, Rao PH, Cardiff RD \& Li Y 2013 Contribution of an alveolar cell of origin to the high-grade malignant phenotype of pregnancy-associated breast cancer. Oncogene 33 5729-5739. (doi:10.1038/onc.2013.521)

Hein SM, Haricharan S, Johnston AN, Toneff MJ, Reddy JP, Dong J, Bu W \& Li Y 2015 Luminal epithelial cells within the mammary gland can produce basal cells upon oncogenic stress. Oncogene [in press]. (doi:10.1038/onc.2015.206)

Herschkowitz JI, Simin K, Weigman VJ, Mikaelian I, Usary J, Hu Z, Rasmussen KE, Jones LP, Assefnia S, Chandrasekharan S et al. 2007 Identification of conserved gene expression features between murine mammary carcinoma models and human breast tumors. Genome Biology 8 R76. (doi:10.1186/gb-2007-8-5-r76)

Herschkowitz JI, Zhao W, Zhang M, Usary J, Murrow G, Edwards D, Knezevic J, Greene SB, Darr D, Troester MA et al. 2012 Comparative oncogenomics identifies breast tumors enriched in functional tumorinitiating cells. PNAS 109 2778-2783. (doi:10.1073/pnas.1018862108)

Hinck L \& Silberstein GB 2005 Key stages in mammary gland development: the mammary end bud as a motile organ. Breast Cancer Research $\mathbf{7}$ 245-251. (doi:10.1186/bcr1331) 
Hollier BG, Tinnirello AA, Werden SJ, Evans KW, Taube JH, Sarkar TR, Sphyris N, Shariati M, Kumar SV, Battula VL et al. 2013 FOXC2 expression links epithelial-mesenchymal transition and stem cell properties in breast cancer. Cancer Research 73 1981-1992. (doi:10.1158/0008-5472.CAN-12-2962)

Huo Y \& Macara IG 2014 The Par3-like polarity protein Par3L is essential for mammary stem cell maintenance. Nature Cell Biology 16 529-537. (doi:10.1038/ncb2969)

Iliopoulos D, Hirsch HA, Wang G \& Struhl K 2011 Inducible formation of breast cancer stem cells and their dynamic equilibrium with non-stem cancer cells via IL6 secretion. PNAS 108 1397-1402. (doi:10.1073/pnas. 1018898108)

Incassati A, Chandramouli A, Eelkema R \& Cowin P 2010 Key signaling nodes in mammary gland development and cancer: $\beta$-catenin. Breast Cancer Research 12 213. (doi:10.1186/bcr2723)

Inman JL, Robertson C, Mott JD \& Bissell MJ 2015 Mammary gland development: cell fate specification, stem cells and the microenvironment. Development 142 1028-1042. (doi:10.1242/dev.087643)

Ismail PM, Li J, DeMayo FJ, O'Malley BW \& Lydon JP 2002 A novel LacZ reporter mouse reveals complex regulation of the progesterone receptor promoter during mammary gland development. Molecular Endocrinology 16 2475-2489. (doi:10.1210/me.2002-0169)

Jackson HW, Waterhouse P, Sinha A, Kislinger T, Berman HK \& Khokha R 2015 Expansion of stem cells counteracts age-related mammary regression in compound Timp1/Timp3 null mice. Nature Cell Biology $\mathbf{1 7}$ 217-227. (doi:10.1038/ncb3118)

Joshi PA, Jackson HW, Beristain AG, Di Grappa MA, Mote PA, Clarke CL, Stingl J, Waterhouse PD \& Khokha R 2010 Progesterone induces adult mammary stem cell expansion. Nature 465 803-807. (doi:10.1038/ nature09091)

Joshi PA, Waterhouse PD, Kannan N, Narala S, Fang H, Di Grappa MA, Jackson HW, Penninger JM, Eaves C \& Khokha R 2015 RANK signaling amplifies WNT-responsive mammary progenitors through R-SPONDIN1. Stem Cell Reports 5 31-44. (doi:10.1016/j.stemcr.2015.05.012)

Kessenbrock K, Dijkgraaf GJ, Lawson DA, Littlepage LE, Shahi P, Pieper U \& Werb Z 2013 A role for matrix metalloproteinases in regulating mammary stem cell function via the Wnt signaling pathway. Cell Stem Cell 13 300-313. (doi:10.1016/j.stem.2013.06.005)

Kordon EC \& Smith GH 1998 An entire functional mammary gland may comprise the progeny from a single cell. Development 125 1921-1930.

Kouros-Mehr H \& Werb Z 2006 Candidate regulators of mammary branching morphogenesis identified by genome-wide transcript analysis. Developmental Dynamics 235 3404-3412. (doi:10.1002/ dvdy.20978)

Lemmen JG, Broekhof JL, Kuiper GG, Gustafsson JA, van der Saag PT \& van der Burg B 1999 Expression of estrogen receptor $\alpha$ and $\beta$ during mouse embryogenesis. Mechanisms of Development 81 163-167. (doi:10.1016/ S0925-4773(98)00223-8)

Li L \& Clevers H 2010 Coexistence of quiescent and active adult stem cells in mammals. Science 327 542-545. (doi:10.1126/science.1180794)

Lim E, Vaillant F, Wu D, Forrest NC, Pal B, Hart AH, Asselin-Labat ML, Gyorki DE, Ward T, Partanen A et al. 2009 Aberrant luminal progenitors as the candidate target population for basal tumor development in BRCA1 mutation carriers. Nature Medicine 15 907-913. (doi:10.1038/ $\mathrm{nm} .2000)$

Liu S, Cong Y, Wang D, Sun Y, Deng L, Liu Y, Martin-Trevino R, Shang L, McDermott SP, Landis MD et al. 2014 Breast cancer stem cells transition between epithelial and mesenchymal states reflective of their normal counterparts. Stem Cell Reports 2 78-91. (doi:10.1016/j.stemcr.2013. 11.009)

Luo M, Zhao X, Chen S, Liu S, Wicha MS \& Guan JL 2013 Distinct FAK activities determine progenitor and mammary stem cell characteristics. Cancer Research 73 5591-5602. (doi:10.1158/0008-5472.CAN-13-1351)

Malanchi I, Santamaria-Martínez A, Susanto E, Peng H, Lehr H-A, Delaloye J-F \& Huelsken J 2012 Interactions between cancer stem cells and their niche govern metastatic colonization. Nature 481 85-89. (doi:10.1038/ nature10694)

Mallepell S, Krust A, Chambon P \& Brisken C 2006 Paracrine signaling through the epithelial estrogen receptor $\alpha$ is required for proliferation and morphogenesis in the mammary gland. PNAS 103 2196-2201. (doi:10.1073/pnas.0510974103)

Mani SA, Guo W, Liao MJ, Eaton EN, Ayyanan A, Zhou AY, Brooks M, Reinhard F, Zhang CC, Shipitsin M et al. 2008 The epithelialmesenchymal transition generates cells with properties of stem cells Cell 133 704-715. (doi:10.1016/j.cell.2008.03.027)

Maria E, Giulia A, Giacobbe A, Peschiaroli A \& Frezza V 2015 p63 sustains self-renewal of mammary cancer stem cells through regulation of Sonic Hedgehog signaling. PNAS 112 3499-3504. (doi:10.1073/pnas. 1500762112

Molyneux G, Geyer FC, Magnay FA, McCarthy A, Kendrick H, Natrajan R, Mackay A, Grigoriadis A, Tutt A, Ashworth A et al. 2010 BRCA1 basallike breast cancers originate from luminal epithelial progenitors and not from basal stem cells. Cell Stem Cell 7 403-417. (doi:10.1016/j.stem. 2010.07.010)

Oakes SR, Naylor MJ, Asselin-Labat ML, Blazek KD, Gardiner-Garden M, Hilton HN, Kazlauskas M, Pritchard MA, Chodosh LA, Pfeffer PL et al. 2008 The Ets transcription factor Elf5 specifies mammary alveolar cell fate. Genes and Development 22 581-586. (doi:10.1101/gad.1614608)

Pal B, Bouras T, Shi W, Vaillant F, Sheridan JM, Fu N, Breslin K, Jiang K, Ritchie ME, Young M et al. 2013 Global changes in the mammary epigenome are induced by hormonal cues and coordinated by Ezh2. Cell Reports 3 411-426. (doi:10.1016/j.celrep.2012.12.020)

Pece S, Tosoni D, Confalonieri S, Mazzarol G, Vecchi M, Ronzoni S, Bernard L, Viale G, Pelicci PG \& Di Fiore PP 2010 Biological and molecular heterogeneity of breast cancers correlates with their cancer stem cell content. Cell 140 62-73. (doi:10.1016/j.cell.2009.12.007)

Perou CM, Sorlie T, Eisen MB, van de Rijn M, Jeffrey SS, Rees CA, Pollack JR, Ross DT, Johnsen H, Akslen LA et al. 2000 Molecular portraits of human breast tumours. Nature 406 747-752. (doi:10.1038/35021093)

Petersen OW \& Polyak K 2010 Stem cells in the human breast. Cold Spring Harbor Perspectives in Biology 2 15. (doi:10.1101/cshperspect. a003160)

Pfefferle AD, Herschkowitz JI, Usary J, Harrell JC, Spike BT, Adams JR, Torres-Arzayus MI, Brown M, Egan SE, Wahl GM et al. 2013 Transcriptomic classification of genetically engineered mouse models of breast cancer identifies human subtype counterparts. Genome Biology 14 R125.

Pfefferle AD, Spike BT, Wahl GM \& Perou CM 2015 Luminal progenitor and fetal mammary stem cell expression features predict breast tumor response to neoadjuvant chemotherapy. Breast Cancer Research and Treatment 149 425-437. (doi:10.1007/s10549-014-3262-6)

Prat A \& Perou CM 2010 Deconstructing the molecular portraits of breast cancer. Molecular Oncology 5 5-23. (doi:10.1016/j.molonc.2010. 11.003)

Prat A, Adamo B, Cheang MCU, Anders CK, Carey LA \& Perou CM 2013 Molecular characterization of basal-like and non-basal-like triplenegative breast cancer. Oncologist 18 123-133. (doi:10.1634/theoncologist.2012-0397)

Prater MD, Petit V, Alasdair Russell I, Giraddi RR, Shehata M, Menon S, Schulte R, Kalajzic I, Rath N, Olson MF et al. 2014 Mammary stem cells have myoepithelial cell properties. Nature Cell Biology 16 942-950. (doi:10.1038/ncb3025)

Proia TA, Keller PJ, Gupta PB, Klebba I, Jones AD, Sedic M, Gilmore H, Tung N, Naber SP, Schnitt S et al. 2011 Genetic predisposition directs breast cancer phenotype by dictating progenitor cell fate. Cell Stem Cell 8 149-163. (doi:10.1016/j.stem.2010.12.007)

Rajaram RD, Buric D, Caikovski M, Ayyanan A, Rougemont J, Shan J, Vainio SJ, Yalcin-Ozuysal O \& Brisken C 2015 Progesterone and Wnt4 control mammary stem cells via myoepithelial crosstalk. EMBO Journal 34 641-652. (doi:10.15252/embj.201490434) 
Regan JL, Sourisseau T, Soady K, Kendrick H, McCarthy A, Tang C, Brennan K, Linardopoulos S, White DE \& Smalley MJ 2013 Aurora a kinase regulates mammary epithelial cell fate by determining mitotic spindle orientation in a notch-dependent manner. Cell Reports 4 110-123. (doi:10.1016/j.celrep.2013.05.044)

Rios AC, Fu NY, Lindeman GJ \& Visvader JE 2014 In situ identification of bipotent stem cells in the mammary gland. Nature 506 322-327. (doi:10.1038/nature12948)

Roarty K, Shore AN, Creighton CJ \& Rosen JM 2015 Ror2 regulates branching, differentiation, and actin-cytoskeletal dynamics within the mammary epithelium. Journal of Cell Biology 208 351-366. (doi:10.1083/jcb.201408058)

Rodilla V, Dasti A, Huyghe M \& Lafkas D 2015 Luminal progenitors restrict their lineage potential during mammary gland development. PLoS Biology 13 e1002069. (doi:10.1371/journal.pbio.1002069)

Rosen JM \& Jordan CT 2009 The increasing complexity of the cancer stem cell paradigm. Science 324 1670-1673. (doi:10.1126/science. 1171837)

Russo J \& Russo IH 1980 Influence of differentiation and cell kinetics on the susceptibility of the rat mammary gland to carcinogenesis influence of differentiation and cell kinetics on the susceptibility of the rat mammary gland to carcinogenesis. Cancer Research 40 2677-2687.

Russo J, Ao X, Grill C \& Russo IH 1999 Pattern of distribution of cells positive for estrogen receptor a and progesterone receptor in relation to proliferating cells in the mammary gland. Breast Cancer Research and Treatment 53 217-227. (doi:10.1023/A:1006186719322)

Sale S \& Pavelic K 2015 Mammary lineage tracing: the coming of age. Cellular and Molecular Life Sciences 72 1577-1583. (doi:10.1007/s00018014-1817-7)

Šale S, Lafkas D \& Artavanis-Tsakonas S 2013 Notch2 genetic fate mapping reveals two previously unrecognized mammary epithelial lineages. Nature Cell Biology 15 1-11. (doi:10.1038/ncb2725)

Sato T, Vries RG, Snippert HJ, van de Wetering M, Barker N, Stange DE, van Es JH, Abo A, Kujala P, Peters PJ et al. 2009 Single Lgr5 stem cells build crypt-villus structures in vitro without a mesenchymal niche. Nature 459 262-265. (doi:10.1038/nature07935)

Sato T, van Es JH, Snippert HJ, Stange DE, Vries RG, van den Born M, Barker N, Shroyer NF, van de Wetering M \& Clevers H 2011 Paneth cells constitute the niche for Lgr5 stem cells in intestinal crypts. Nature $\mathbf{4 6 9}$ 415-418. (doi:10.1038/nature09637)

Seagroves TN, Lydon JP, Hovey RC, Vonderhaar BK \& Rosen JM 2000 C/EBP $\beta$ (CCAAT/enhancer binding protein) controls cell fate determination during mammary gland development. Molecular Endocrinology 14 359-368. (doi:10.1210/mend.14.3.0434)

Shackleton M, Vaillant F, Simpson KJ, Stingl J, Smyth GK, Asselin-Labat M-L, Wu L, Lindeman GJ \& Visvader JE 2006 Generation of a functional mammary gland from a single stem cell. Nature $\mathbf{4 3 9} 84-88$ (doi:10.1038/nature04372)

Shah SP, Roth A, Goya R, Oloumi A, Ha G, Zhao Y, Turashvili G, Ding J, Tse K, Haffari G et al. 2012 The clonal and mutational evolution spectrum of primary triple-negative breast cancers. Nature 486 395-399. (doi:10.1038/nature10933)

Shehata M, Teschendorff A, Sharp G, Novcic N, Russell IA, Avril S, Prater M, Eirew P, Caldas C, Watson CJ et al. 2012 Phenotypic and functional characterisation of the luminal cell hierarchy of the mammary gland. Breast Cancer Research 14 R134. (doi:10.1186/bcr3334)

Shehata M, van Amerongen R, Zeeman AL, Giraddi RR \& Stingl J 2014 The influence of tamoxifen on normal mouse mammary gland homeostasis. Breast Cancer Research 16 411. (doi:10.1186/s13058014-0411-0)

Shipitsin M, Campbell LL, Argani P, Weremowicz S, Bloushtain-Qimron N, Yao J, Nikolskaya T, Serebryiskaya T, Beroukhim R, Hu M et al. 2007 Molecular definition of breast tumor heterogeneity. Cancer Cell $\mathbf{1 1}$ 259-273. (doi:10.1016/j.ccr.2007.01.013)

Skibinski A, Breindel JL, Prat A, Galvan P, Smith E, Rolfs A, Gupta PB, Labaer J \& Kuperwasser C 2014 The Hippo transducer TAZ interacts with the
SWI/SNF complex to regulate breast epithelial lineage commitment. Cell Reports 6 1059-1072. (doi:10.1016/j.celrep.2014.02.038)

Smith GH \& Medina D 1988 A morphologically distinct candidate for an epithelial stem cell in mouse mammary gland. Journal of Cell Science $\mathbf{9 0}$ 173-183.

Soady KJ, Kendrick H, Gao Q, Tutt A, Zvelebil M, Ordonez LD, Quist J, Tan DW, Isacke CM, Grigoriadis A et al. 2015 Mouse mammary stem cells express prognostic markers for triple-negative breast cancer. Breast Cancer Research 17 31. (doi:10.1186/s13058-015-0539-6)

Sorlie T, Perou CM, Tibshirani R, Aas T, Geisler S, Johnsen H, Hastie T, Eisen MB, van de Rijn M, Jeffrey SS et al. 2001 Gene expression patterns of breast carcinomas distinguish tumor subclasses with clinical implications. PNAS 98 10869-10874. (doi:10.1073/pnas. 191367098)

Spike BT, Engle DD, Lin JC, Cheung SK, La J \& Wahl GM 2012 A mammary stem cell population identified and characterized in late embryogenesis reveals similarities to human breast cancer. Cell Stem Cell 10 183-197. (doi:10.1016/j.stem.2011.12.018)

Stephens PJ, Tarpey PS, Davies H, Van Loo P, Greenman C, Wedge DC, Nik-Zainal S, Martin S, Varela I, Bignell GR et al. 2012 The landscape of cancer genes and mutational processes in breast cancer. Nature $\mathbf{4 8 6}$ 400-404. (doi:10.1038/nature11017)

Stingl J, Eaves CJ, Zandieh I \& Emerman JT 2001 Characterization of bipotent mammary epithelial progenitor cells in normal adult human breast tissue. Breast Cancer Research and Treatment 67 93-109. (doi:10.1023/A:1010615124301)

Stingl J, Eirew P, Ricketson I, Shackleton M, Vaillant F, Choi D, Li HI \& Eaves CJ 2006 Purification and unique properties of mammary epithelial stem cells. Nature 439 993-997. (doi:10.1038/nature04496)

Tanos T, Sflomos G, Echeverria PC, Ayyanan A, Gutierrez M, Delaloye JF, Raffoul W, Fiche M, Dougall W, Schneider P et al. 2013 Progesterone/RANKL is a major regulatory axis in the human breast. Science Translational Medicine 5 182ra55. (doi:10.1126/scitranslmed. 3005654)

Taube JH, Herschkowitz JI, Komurov K, Zhou AY, Gupta S, Yang J, Hartwell K, Onder TT, Gupta PB, Evans KW et al. 2010 Core epithelialto-mesenchymal transition interactome gene-expression signature is associated with claudin-low and metaplastic breast cancer subtypes. PNAS 107 15449-15454. (doi:10.1073/pnas.1004900107)

TCGA 2012 Comprehensive molecular portraits of human breast tumours. Nature 490 61-70. (doi:10.1038/nature11412)

Van Keymeulen A, Rocha AS, Ousset M, Beck B, Bouvencourt G, Rock J, Sharma N, Dekoninck S \& Blanpain C 2011 Distinct stem cells contribute to mammary gland development and maintenance. Nature 479 189-193. (doi:10.1038/nature10573)

Veltmaat JM, Mailleux AA, Thiery JP \& Bellusci S 2003 Mouse embryonic mammogenesis as a model for the molecular regulation of pattern formation. Differentiation 71 1-17. (doi:10.1046/j.1432-0436.2003. 700601.x)

Vieira AF, Ricardo S, Ablett MP, Dionísio MR, Mendes N, Albergaria A, Farnie G, Gerhard R, Cameselle-Teijeiro JF, Seruca R et al. 2012 $\mathrm{P}$-cadherin is coexpressed with CD44 and CD49f and mediates stem cell properties in basal-like breast cancer. Stem Cells 30 854-864. (doi:10.1002/stem.1075)

Visvader JE \& Stingl J 2014 Mammary stem cells and the differentiation hierarchy: current status and perspectives. Genes and Development 28 1143-1158. (doi:10.1101/gad.242511.114)

Wang D, Cai C, Dong X, Yu QC, Zhang X-O, Yang L \& Zeng YA 2014 Identification of multipotent mammary stem cells by protein $\mathrm{C}$ receptor expression. Nature $\mathbf{5 1 7}$ 81-84. (doi:10.1038/nature13851)

Wei W, Tweardy DJ, Zhang M, Zhang X, Landua J, Petrovic I, Bu W, Roarty K, Hilsenbeck SG, Rosen JM et al. 2014 STAT3 signaling is activated preferentially in tumor-initiating cells in claudin-low models of human breast cancer. Stem Cells 32 2571-2582. (doi:10.1002/stem. 1752)

Published by Bioscientifica Ltd. 
Welm BE, Tepera SB, Venezia T, Graubert TA, Rosen JM \& Goodell MA 2002 Sca-1(pos) cells in the mouse mammary gland represent an enriched progenitor cell population. Developmental Biology 245 42-56. (doi:10.1006/dbio.2002.0625)

Williams JM \& Daniel CW 1983 Mammary ductal elongation: differentiation of myoepithelium and basal lamina during branching morphogenesis. Developmental Biology 97 274-290. (doi:10.1016/00121606(83)90086-6)

Zeng YA \& Nusse R 2010 Wnt proteins are self-renewal factors for mammary stem cells and promote their long-term expansion in culture. Cell Stem Cell 6 568-577. (doi:10.1016/j.stem.2010.03.020)

Zhang M, Behbod F, Atkinson RL, Landis MD, Kittrell F, Edwards D, Medina D, Tsimelzon A, Hilsenbeck S, Green JE et al. 2008 Identification of tumor-initiating cells in a p53-null mouse model of breast cancer. Cancer Research 68 4674-4682. (doi:10.1158/0008-5472. CAN-07-6353)

Zhang M, Atkinson RL \& Rosen JM 2010 Selective targeting of radiationresistant tumor-initiating cells. PNAS 107 3522-3527. (doi:10.1073/ pnas.0910179107)

Zhang M, Tsimelzon A, Chang CH, Fan C, Wolff A, Perou CM, Hilsenbeck SG \& Rosen JM 2015 Intratumoral heterogeneity in a Trp53-null mouse model of human breast cancer. Cancer Discovery 5 520-533. (doi:10.1158/2159-8290.CD-14-1101)

Zvelebil M, Oliemuller E, Gao Q, Wansbury O, Mackay A, Kendrick H, Smalley MJ, Reis-Filho JS \& Howard BA 2013 Embryonic mammary signature subsets are activated in Brca1-/- and basal-like breast cancers. Breast Cancer Research 15 R25. (doi:10.1186/ bcr3403)

Received in final form 17 July 2015

Accepted 23 July 2015

Made available online as an Accepted Preprint

23 July 2015
Published by Bioscientifica Ltd. 